\title{
Политические предпочтения: эффект экономической уязвимости
}

\author{
C.А. КОРОТАЕВ*, Е.Н. ГАСЮКОВА**
}

\begin{abstract}
*Сергей Александрович Коротаев - научный сотрудник, Национальный исследовательский университет «Высшая школа экономики», skorotaev@hse.ru, https://orcid.org/0000-0002-7038-2759

**Елена Николаевна Гасюкова - младший научный сотрудник, Национальный исследовательский университет «Высшая школа экономики», egasyukova@hse.ru, https://orcid.org/0000-0001-6938-5218
\end{abstract}

Цитирование: Коротаев С.А., Гасюкова Е.Н. (2022) Политические предпочтения: эффект экономической уязвимости // Мир России. Т. 31. № 1. С. 138-161. DOI: $10.17323 / 1811-038 X-2022-31-1-138-161$

\begin{abstract}
Аннотация
В статье исследуются воздействующие на политические предпочтения факторы с точки зрения трех конкурирующих теоретических подходов. Формирование политических воззрений может интерпретироваться в терминах социализации (политические предпочтения отражают здравый смысл и представления о должном и правильном, усвоенные в прочессе сочиализации), утилитаристского взгляда (политические предпочтения как отражение эгоистического интереса индивидов), психологических механизмов (реакиия на неопределенность и угрозу). Авторы проводят сопоставление объяснительной силь указанных подходов на примере уязвимых индивидов, используя данные Российского мониторинга экономического положения и здоровья населения НИУ ВШЭ 2015 года. В качестве меры уязвимости респондентов использованы несколько показателей: трудовая нестабильность, страх потери работы и неспособности обеспечить свою жизнь в ближайшем будущем. Фокус на экономически уязвимых респондентах позволяет выявить те сочиальные предпочтения, которые в разрезе концепции охранительных благ могут быть ассочиированы как отвечающие за сохранение и укрепление социального порядка. Исследуемое авторами политическое пространство строится на двух осях, полученных в результате факторного анализа, и включает предпочтения в сфере экономики (роль государства и частного сектора) и в сочиальной сфере (отношение к мигрантам). Результаты регрессионного анализа демонстрируют значимость субъективного восприятия
\end{abstract}

Исследование выполнено за счет гранта РНФ (проект № 16-18-10270). Авторы выражают искреннюю благодарность С.Б. Соколовой (ЗАО «Демоскоп») за предоставление необходимых для анализа данных РМЭЗ НИУ ВШЭ.

Статья поступила в редакцию в сентябре 2020 г. 
уязвимости в сфере занятости и материального благополучия. Уязвимые респонденть, испытывающие страх потерять работу, ориентированы на левую экономическую политику и менее толерантны к мигрантам. Трудовая нестабильность как таковая значимого влияния на политические представления не оказывает. В заключении статьи авторы также обращаются к обсуждению ограничений исследования.

Ключевые слова: политические предпочтения, политическая идеология, политическая психология, сочиальная структура, нестабильная занятость, прагматический интерес, соичализация

В социальных науках принято говорить о политических предпочтениях как достаточно устойчивых диспозициях, отражающих здравый смысл, нормативные принципы некоторой группы или сообщества, с которым индивид разделяет эти нормы [Zuckerman et al. 1998; Janoff-Bulman, Carnes 2016]. Политические предпочтения медленно трансформируются в ходе создания и конкуренции идей и смыслов в публичной сфере [Bornschier 2010], их эксплуатации акторами, конкурирующими в сфере политики [Kriesi et al. 2006], избирательной рецепции идей и концепций широкими слоями, определяемой социальной принадлежностью реципиентов [Dalton 2013], а следовательно, и изменяющейся социальной структурой, которая формируется также под влиянием политического процесса [Latimer, Munro 2015]. Такой взгляд делает крайне актуальным изучение политических предпочтений граждан как отражение некоторой консенсусной морали, легитимирующей одни политические возможности и дискредитирующей другие.

Но так ли бесспорна представленная картина? Отметим существование альтернативных подходов к рассмотрению политических предпочтений, предлагающих иные механизмы их формирования и экспликации. Так, утилитаристский взгляд представляет политические предпочтения как отражение эгоистического интереса индивидов, обладающих различными наборами ресурсов: обеспеченные стремятся к сохранению статус-кво, лишенные - к перераспределению [Guillaud 2013; Harrits et al. 2010]. В этом случае исследование политических предпочтений оказывается несколько избыточным или, по крайней мере, вторичным по отношению к исследованиям социального и экономического неравенства. Третья позиция предлагает искать причины выбора индивидом определенной политической позиции в его психологических свойствах [Jost et al. 2009; Oxley et al. 2008], подверженных изменениям в ответ на ситуации стресса или угрозы [Gadarian 2010]. В этом случае политические предпочтения отражают уже не (только) рациональные аргументы, базирующиеся на общеразделяемом здравом смысле, но и подсознательную реакцию на перенесенный стресс или переживаемые страхи [Bonanno, Jost 2006].

Дополнительная актуальность озвученной дискуссии в отношении российского случая обусловлена тем, что принятие той или иной политической позиции не является инструментом политической конкуренции [Гельман 2020; Smyth 2012]. Индифферентность к идеологическим различиям политиков неизбежно влечет индифферентность граждан (или же обусловлена ею) [Wilson 2012]; не вдаваясь в дискуссию о генезисе этой ситуации, отметим, что она потенциально повышает значимость альтернативных факторов политических предпочтений. 
Представленная статья обращается к трем указанным подходам в объяснении политических предпочтений. Используя данные Российского мониторинга экономического положения и здоровья населения НИУ ВШЭ, авторы стремятся понять, какой из подходов наилучшим образом описывает политические предпочтения россиян. Особое внимание в работе уделено факторам экономической уязвимости. Во-первых, показатели уязвимости позволяют «столкнуть» альтернативные подходы, сформулировав на их основе взаимоисключающие гипотезы относительно эффекта уязвимости. Во-вторых, проблематика экономической уязвимости в контексте политических движений и трансформаций занимает стабильно видное место как в академическом [Стэндинг 2014], так и публичном дискурсе: экономические потрясения вызывают страх или надежду как катализаторы резких социально-политических трансформаций.

\section{Трудовая уязвимость}

Понятие уязвимости рассматривается нами как ситуативное состояние риска, как опасения индивида лишиться способности соответствовать ожиданиям его окружения и вести привычный образ жизни. Как и другие исследователи (например, [Mackenzie 2014]), мы считаем важным разграничивать понятия уязвимости на те, которые относятся к универсальным рискам, сопровождающим жизнь любого человека (все из нас подвержены риску болезни, потери родственника и т. д.), и те, которые обусловлены конъюнктурой, обстоятельствами или изменениями, грозящими в глазах индивида риском социального падения, экономической депривации. Мы опираемся на второе понимание уязвимости: уязвимость как характеристика конкретных обстоятельств индивида, например как вероятность падения в бедность, но не пребывание в ней [Torche, Lopez-Calva 2013].

В статье в качестве меры уязвимости использованы несколько показателей: трудовая нестабильность, страх потери работы и неспособности обеспечить свою жизнь в ближайшем будущем. Трудовая нестабильность, понимаемая как неоднократная смена работы или постоянные переходы в статус безработного в течение нескольких лет, преимущественно исследуется с позиций социальной уязвимости, сопряженной с финансовыми трудностями, откладыванием планов, отсутствием профессионального развития, проблемами в семье [Migliavacca 2010; Glauber 2013; Карабчук 2008]. Два других показателя отсылают к субъективным переживаниям, рассматриваемым не как отражение некоторых черт характера, скажем, мнительности, но и как следствие реальных обстоятельств респондента. Исследователи признают [Гимпельсон, Ощепков 2011, с. 301], что страхи россиян реагируют на макроконъюнктурные условия (стабильность 2000-х до кризиса 2008 г. и рост в период кризиса). При этом в 2000-х гг. не было обнаружено связи между страхом потери работы и фактической безработицей [Гимпельсон, Ощелков 2011], указывающей, по нашему мнению, на то, что страх не является лишь эпифеноменом безработицы, но охватывает более широкий набор реакций на угрожающие обстоятельства, например, готовность терпеть плохие условия труда, задержки заработной платы, переработки, неоплачиваемые отпуска ради сохранения работы, невозможность финансового планирования. В то же время 
на данных 2006-2015 гг. агрегированные значения субъективных оценок трудовой уязвимости и фактической безработицы демонстрируют синфазность: периоды роста субъективных оценок приходятся на периоды роста безработицы. Особенно это верно в отношении опасений «не найти работу» (рисунок 1). Таким образом, в дальнейшем анализе мы исходим из наличия связи объективной уязвимости и ее субъективного переживания.

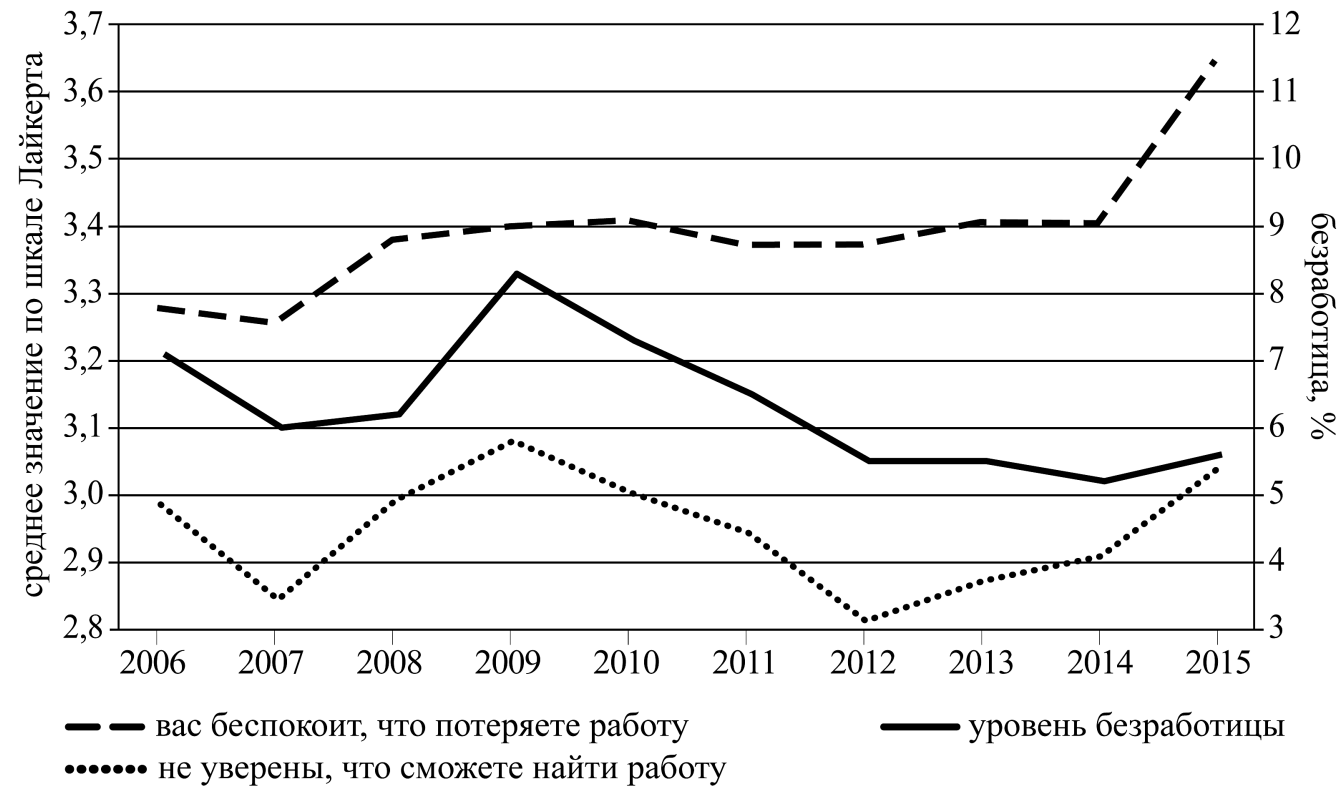

Рисунок 1. Динамика субъективных и объективных показателей трудового положения работников

[Безработица в России 2015, с. 5]; субъективные показатели рассчитаны как средние по выборке значения по пятибалльной шкале Лайкерта (большее значение соответствует большей степени согласия) вопросов РМЭЗ за 2006-2015 гг.

\section{Пространство политических предпочтений}

Теоретически структура идеологического пространства ${ }^{1 *}$ может быть обоснована «снизу» как отражение структуры психологических свойств личности (напр., [Feldman, Johnston 2014]) или «сверху» как результат конкуренции политически агентов (партий) [Marks et al. 2006; Kriesi et al. 2006; Bornschier 2010; Wheatley 2015]; наконец, такая структура может быть получена из некоторых априорных представлений о том, что является политикой (напр., [Kitschelt, Rehm 2014]). Комментаторы отмечают появление т. н. новых левых партий в 1970-е гг. как ответ на социальные движения 1960-1970-х гг., обусловленные изменениями социальной структуры. Новые партии стремились привлечь электорат, индифферентный к прежним линиям

1* Здесь и далее примечания, обозначенные астериском, размещены в приложении 5 на сайте журнала. 
раскола по вопросу экономического неравенства и перераспределения (левые правые), что вызвало появление новой оси идеологического позиционирования. Новая ось, назовем ее социальной, противопоставляла сторонников личных свобод и гражданских прав для всех, с одной стороны, а с другой - приверженцев прежнего порядка, чье политическое оформление (новые правые) произошло несколько позже, причем катализатором стала прежде неактуальная иммиграционная повестка [Bornschier 2010; Kriesi et al. 2006]. Таким образом, в настоящий момент две оси (редистрибуция vs свободный рынок; универсализм, равноправие, толерантность vs традиционные ценности, защита сообщества) удовлетворительно описывают поле конкуренции партий в странах Европы [Wheatley 2015], что верно не только в отношении устоявшихся демократий, но и новых членов ЕС [Marks et al. 2006].

Сторонники примата психологии рассматривают вариацию мнений по политическим вопросам как отражение структуры более или менее стабильных психологических качеств. Наиболее часто при анализе политического пространства авторы (напр. [Aspelund et al. 2013; Feldman, Johnston 2014] ссылаются на ценности Шварца ${ }^{2 *}$, а также шкалы, измеряющие предрасположенность к авторитаризму (Right-Wing Authoritarianism, RWA) [Altemeyer 1998] ${ }^{2}$ и социальному доминированию (social dominance orientation, SDO) [Pratto et al. 1994]³. Указывается концептуальное сходство шкал SDO и RWA с экономической и социальными осями идеологии [Feldman, Johnston 2014]. Исследования демонстрируют связь перечисленных индикаторов с различными мерами политических предпочтений ${ }^{3 *}$ [Duriez et al. 2005; Vasilopoulos, Lachat 2018; Aspelund et al. 2013]. В развитых странах авторитаристы привержены традиционным капиталистическим ценностям, т. е. занимают правую позицию на экономической оси, а во многих постсоциалистических странах традиционными являются коммунистические ценности, т. е. авторитаристы там - левые [Duriez et al. 2005] $]^{4 *}$.

Дж. Джост в своем влиятельном подходе стремится объединить взгляды «снизу вверх» и «сверху вниз». Он соглашается с тем, что идеологии производятся конкурирующими элитами и в дискурсивном виде транслируются избирателям, формируя своего рода ассортимент доступных идей [Jost et al. 2009]. Граждане выбирают из уже готового набора, но предпочитают те идеи, которые более соответствуют их устойчивым (в некоторой степени генетически обусловленным) психологическим склонностям. Ценность этого выбора для них состоит в том, что идеология помогает решить базовые психологические потребности: рационализирует и структурирует реальность, дает чувство защищенности и обеспечивает солидарность. Модель объясняет вариативность связи между политическими предпочтениями и психологическими предрасположенностями (RWA, SDO, ценности Шварца и др.), предполагая историческую контингентность первых и универсальность вторых. Впрочем, изменение структуры психологических предрасположенностей под действием существующих идеологий также возможно [Duriez et al. 2005].

\footnotetext{
2 RWA предполагает оценку трех измерений: склонность подчиняться властям (авторитарное подчинение); агрессивная настроенность по отношению к аутгруппам (авторитарная агрессия), поддержка традиционных ценностей (конвенционализм). Высокое значение RWA означает стремление сохранить текущий общественный порядок. Некоторые авторы используют вместо шкалы RWA иные меры авторитаризма; ради простоты изложения мы их все именуем как RWA.

3 SDO предполагают одну ось измерения, на одном полюсе которой располагаются индивиды, выступающие за принципы равенства, ценности альтруизма, всеобщего благополучия, на другом - за иерархическое строение общества, высокую дистанцию власти, принципы доминирования.
} 
Таким образом, существует широкий консенсус по поводу принципиальной организации пространства политических предпочтений. Авторы, задающие это пространство, исходя из некоторых априорных соображений, как и те, кто следует эмпирическим закономерностям анализируемых данных (data driven), за редким исключением (напр., [Jost et al. 2009]), сходятся в том, что пространство политических предпочтений может быть описано с помощью двух осей ${ }^{5^{*}}$ [Evans et al. 1996; Feldman, Johnston 2014]. Первая из них охватывает предпочтения в сфере экономики - редистрибуция, власть рынка или контроль государства. Вторая - права сексуальных меньшинств, гендерное равноправие (в т. ч. аборты), отсутствие цензуры, универсальные ценности, положительное отношение к иммигрантам против поддержания традиционных норм и ценностей, партикуляризма, ограничений на иммиграцию и требование аккультурации. В предложенной статье такой взгляд принят как отправная точка. В дальнейшем мы будем обозначать оси как экономический и социальный консерватизм, именуя консервативный полюс обеих осей правым, а противоположный ему - левым.

\section{Социализация и политические предпочтения}

Исследователи, акцентирующие роль структурных позиций индивида ${ }^{6 *}$ [Chan, Goldthorpe 2007; Mochmann, El-Menouar 2005; Evans 1997], исходят из того, что политические предпочтения отражают здравый смысл и представления о должном и правильном, усвоенные в процессе социализации [Бурдье 1993; Lamprianou 2013]. По принадлежности к социальной группе ${ }^{4}$ можно судить о политических предпочтениях индивида: первичная (семья [Clark, Angelo 2010]) и вторичная (образование [Stubager 2008] и работа ${ }^{7 *}$ [Kitschelt, Rehm 2014]) социализация оказывают значимый эффект на политические предпочтения.

Для россиян связь между структурной позицией индивида и его политическими ориентациями оказывается менее явной. В 1990-е гг., когда еще можно было наблюдать конфронтацию политических идеологий [Гельман 2020], не обнаруживалась связь между социальным положением индивида и его политическими воззрениями [Галкин 1998]. С 2000-х г. усиливаются политическая индифферентность населения и разочарование в реформах, в стране формируется консервативное большинство с ориентацией на сильное стабильное государство [Бызов 2014]. Однако есть исследования, обнаруживающие связь политических ориентаций и структурного положения россиянина [Карачаровский, Шкаратан 2020].

С точки зрения социализационного подхода нахождение в ситуации уязвимости не может отменить эффект предшествующей социализации, соответственно:

H1: Ситуация уязвимости не должна оказывать какое-либо влияние на политические предпочтения.

4 А.Т. Бикбов отмечает, что реферирование к понятиям социальных общностей, как правило, сопряжено с наделением индивидов схожими социальными ориентациями [Бикбов 2014, с. 59, 65]. Любая социальная категоризация предполагает априорную гомогенность взглядов, требований со стороны членов одной группы, что дает возможность использовать подобные референции для сопоставления имеющихся в обществе политических оппозиций. 
Отметим, что длительное нахождение в уязвимом положении само оказывается социализирующим фактором, следовательно, уязвимость, вписанная в структурные условия, может влиять на идеологическую позицию. Однако рассмотрение подобных эффектов выходит за рамки данной работы.

\section{Связь прагматических интересов и политических предпочтений}

С точки зрения прагматического интереса восприятие индивидом своих жизненных шансов и текущего экономического положения (соответствующее классовой позиции индивида в обществе), а не ценностные установки воздействуют на политическую идентификацию индивида [Brooks, Svallfors 2010]. Так, среди бедных и безработных в основном находят поддержку левые идеи и уравнительная и перераспределительная политика в экономике [Visser et al. 2014; Owens, Pedulla 2014]. В ситуации неопределенности и потери дохода работники нуждаются в гарантиях занятости и финансовой страховке, именно это они ожидают от левых лидеров [Cusack et al. 2006; Emmenegger et al. 2015]. Помимо объективного, на модификацию политических предпочтений может воздействовать и относительное изменение уровня жизни: если субъективное благополучие растет, то индивид отказывается от идей перераспределения, в обратном случае - начинает придерживаться левых взглядов [Brown-Iannuzzi et al. 2015]. Негативное отношение индивида к мигрантам определяется тем, являются ли они конкурентами индивида за рабочие места или нет [Mayda 2006; Paas, Demidova 2014].

Исследования российских работников также позволили выявить связь прагматического интереса и социальных предпочтений ${ }^{5}$. Требования поддержки исходят от граждан, испытывающих трудности в определенной области жизни и не способных справиться с ними самостоятельно: нестабильно занятых [Тощенко 2017], безработных, работников с низкой переговорной силой, молодежи в поисках достойной работы [Аникин и др. 2019]. Вышесказанное позволяет сформулировать гипотезу:

H2: Ситуация уязвимости связана с формированием у респондентов левых политических убеждений в экономической сфере. При этом влияние уязвимости на позицию по оси социального консерватизма отсутствует.

\section{Психологические механизмы}

Как было сказано, показатели авторитаризма (RWA) оказывают воздействие на политические ориентации [Vasilopoulos, Lachat 2018], в частности, в постсоциалистических странах высокие значения RWA связаны с левыми убеждениями по экономической шкале и правыми в социальной [Duriez et al. 2005;

\footnotetext{
5 С.Г. Кордонский отмечает, что в российском обществе интересы каждого сосредоточены на максимизации того объема ресурсов, который ему положен в соответствии с его местом в сословной иерархии - устойчивым социальным порядком, воспроизводимым при любой власти в России [Кордонский 2008].
} 
McFarland et al. 1996]. На российских данных было выявлено, что высокие значения RWA коррелируют с показателями нетерпимости к мигрантам [Grigoryev et al. 2020].

Современный взгляд на показатели авторитаризма, подобные RWA, предполагает, что они (или их манифестации) чувствительны к контексту. Предполагается, что реакцией на угрозу, травматический опыт или переживание тревоги является рост авторитаризма. Жесткие нормы и принципы выполняют роль защитного механизма в условиях неопределенности, авторитарная ориентация предлагает когнитивно простые, надежные, хотя и не гибкие решения [Jost et al. 2003; Duckitt et al. 2002]. Существует обширная дискуссия о том, какие именно угрозы оказывают влияние на показатели авторитаризма [Feldman 2013]. Следуя ряду авторов [Asbrock, Fritsche 2013], мы полагаем, что угроза личному благополучию, достижению стоящих перед индивидом целей является фактором авторитарных склонностей. Также возможно, что интересующий нас тип угроз вызывает эффект не напрямую, но воздействуя на восприятие иных, более специфических типов угроз (медиирует) (напр., [Shaffer, Duckitt 2013, p. 15]).

Поскольку ситуация трудовой нестабильности, как правило, сопряжена с негативным психологическим состоянием работников: частыми волнениями, стрессом, неуверенностью [Vives et al. 2013], - мы ожидаем, что нестабильные, а также уязвимые по субъективным оценкам работники имеют более высокий при прочих равных уровень RWA, а следовательно:

H3: Нестабильные и экономически уязвимые работники тяготеют к правому полюсу в социальной сфере ${ }^{8 *}$ и левому - в экономической.

\section{Методология}

Исследование выполнено на данных Российского мониторинга экономического положения и здоровья населения (РМЭЗ НИУ ВШЭ) 24-й волны (2015 г.) ${ }^{6}$. Для расчета показателей трудовой нестабильности были дополнительно использованы данные четырех предыдущих волн. Выборка ограничена взрослыми респондентами 24-55 лет включительно; объем выборки составил 5541 респондент.

\section{Политические предпочтения}

Были сконструированы две оси политических предпочтений: (1) экономический консерватизм на основе вопросов о желательности преимущественного участия частного бизнеса или государства в обеспечении общественных благ; (2) социальный консерватизм на основе вопросов об отношении к мигрантам (подробнее см. приложение 1 на сайте журнала).

\section{Трудовая нестабильность}

В работе использованы три показателя уязвимости: трудовая нестабильность, субъективная экономическая уязвимость, субъективная трудовая уязвимость (страх потерять работу).

6 http://www.hse.ru/rlms 
Переменная «нестабильность» строилась на основе данных о статусе занятости респондента (работает - сменил работу/профессию - не работает) в текущем и двух предыдущих годах. Респондент причислялся к нестабильно занятым, если в течение трех лет подряд менял статус занятости не менее 2 раз (см. приложение 1 на сайте журнала).

В отдельных моделях учитывался стаж пребывания в ситуации трудовой нестабильности $-1,2$ и 3 года подряд.

\section{Страх потерять работу}

Идентификатором трудовой уязвимости послужил показатель опасения потерять работу («Насколько Вас беспокоит то, что Вы можете потерять работу?»). Если респондент очень беспокоился по поводу того, что может потерять работу, то он причислялся к уязвимым. Указанный индикатор относится только к тем респондентам, кто имеет работу.

\section{Экономическая уязвимость}

Показателем экономической уязвимости служил ответ респондента на вопрос «насколько Вас беспокоит то, что Вы не сможете обеспечивать себя самым необходимым в ближайшие 12 месяцев?»

\section{Доход}

Сумма всех денежных поступлений домохозяйства за прошедший месяц, приходящаяся на одного взрослого члена семьи (строго старше 23 лет) (данные взяты из опроса домохозяйств 2015 г.), была нормирована на средний доход в данном типе населенного пункта (областной центр, город, ПГТ/село, по данных РМЭЗ); таким образом, житель областного центра, обладающий доходом на 10\% выше среднего для жителей данного типа поселений, имел то же значение переменной, что и житель села, который имел доход, на $10 \%$ превышающий средний среди жителей ПГТ и сел.

\section{Класс}

Профессия респондента операционализировалась с помощью классовой схемы Д. Оеща [Oesch 2006]. Данная классификация имеет две вертикальные градации, отличающиеся уровнем квалификации (менеджеры и (полу)профессионалы, с одной стороны, и рабочие, клерки - с другой), и три горизонтальные, каждая из которых представляет собственную логику труда: техническую (от монтажника до инженера или программиста), организационную (от клерка до менеджера), связанную с межличностным взаимодействием (от помощника в магазине до преподавателя в университете) (см. приложение 1 на сайте журнала).

\section{Субъективное благополучие}

Субъективные оценки респондентов оценивались по шкале Лайкерта, учитывалось восприятие респондентами своего экономического, властного и социального положения в обществе (вопросы № TJ62, ТJ63, ТJ64).

\section{Образование}

Наличие высшего образования фиксируется бинарной переменной. Учитывая широкую распространенность высшего образования и, следовательно, его низкую 
дифференцирующую силу, было решено ввести дополнительный показатель - знание английского языка. Язык выступает одновременно и как характеристика культурного/образовательного статуса, и как индикатор доступа к несравнимо более широкому спектру медиа.

\section{Прочие сочииально-демографические показатели}

Место проживания (областной центр, город, ПГТ/село); возраст (в годах, 24-55 лет включительно); наличие партнера/супруга(и); пол; наличие детей.

\section{Пропущзенные данные}

Построение переменной «трудовая нестабильность» требует данных о респонденте за два предшествующих года. Поскольку существенная доля респондентов 2015 г. не заполняла опросный лист в 2014 или 2013 г., по этой переменной велика доля пропусков.

Предварительный анализ показал (приложения 2, 3 на сайте журнала), что вероятность того, что значение по переменной нестабильность пропущено, не является независимой от значения наших объясняемых переменных (политических предпочтений). Отсюда следует, что результат анализа, ограниченного только респондентами, не имеющими пропущенных данных, будет смещенным. По этой причине анализ был проведен с применением множественной импутации (приложение 2 на сайте журнала).

\section{Результаты}

Базовая модель (таблища 1, модель 1) включает в качестве независимых переменных традиционные предикторы политических предпочтений: маркеры социального положения, места проживания, демографические параметры. Поскольку смысл одних и тех же значений «объективных» показателей может существенно варьироваться в зависимости от места проживания респондента, что не всегда может быть скорректировано простой нормировкой, мы также добавили в список объясняющих переменных субъективные оценки респондентом своего положения на шкалах богатства, власти и престижа.

Начнем с рассмотрения влияния классовой позиции на политические предпочтения. Класс маркируется качественной переменной, имеющей шесть категорий. Конвенциональный формат презентации результатов регрессионного анализа крайне неинформативен в отношении переменных с несколькими категориями, поскольку позволяет видеть значимость различий лишь по отношению к базовой категории, но не предоставляет возможность сравнить между собой любые две другие категории. Решение проблемы было предложено Д. Фиртом [Firth 2003]: он разработал алгоритм, позволяющий подобрать для данной категориальной переменной квазистандартные ошибки так, что стандартную ошибку разности коэффициентов читатель может вычислить самостоятельно как корень суммы квадратов случайных ошибок этих двух коэффициентов. Квазистандартные ошибки представлены в таблище 1, разницы коэффициентов классов изображены на рисунке 2. 
Таблица 1. Факторы политических предпочтений (данные с множественной импутацией)

\begin{tabular}{|c|c|c|c|c|}
\hline & \multicolumn{2}{|c|}{ Модель 1} & \multicolumn{2}{|c|}{ Модель 2} \\
\hline & ЭК & CK & ЭК & CK \\
\hline \multicolumn{5}{|l|}{ Населенный пункт } \\
\hline город & ref. & ref. & ref. & ref. \\
\hline областной центр & $\begin{array}{c}0,030 \\
(0,035)\end{array}$ & $\begin{array}{c}0,043 \\
(0,035)\end{array}$ & $\begin{array}{c}0,009 \\
(0,035)\end{array}$ & $\begin{array}{c}0,053 \\
(0,035)\end{array}$ \\
\hline ПГТ/село & $\begin{array}{l}-0,066 \\
(0,037)\end{array}$ & $\begin{array}{c}0,130 \\
(0,037) * * *\end{array}$ & $\begin{array}{l}-0,064 \\
(0,037)\end{array}$ & $\begin{array}{c}0,129 \\
(0,037)^{* * *}\end{array}$ \\
\hline Высшее образование & $\begin{array}{c}0,061 \\
(0,037)\end{array}$ & $\begin{array}{l}-0,038 \\
(0,037)\end{array}$ & $\begin{array}{c}0,046 \\
(0,037)\end{array}$ & $\begin{array}{l}-0,030 \\
(0,037)\end{array}$ \\
\hline Знание иностранного языка & $\begin{array}{c}0,008 \\
(0,039)\end{array}$ & $\begin{array}{c}-0,092 \\
(0,039)^{*}\end{array}$ & $\begin{array}{c}0,010 \\
(0,039)\end{array}$ & $\begin{array}{c}-0,093 \\
(0,039) *\end{array}$ \\
\hline \multicolumn{5}{|l|}{ Классы Оеща } \\
\hline 3. технические (полу)профессионалы & $\begin{array}{c}\text { ref. } \\
{[0,050]}\end{array}$ & $\begin{array}{c}\text { ref. } \\
{[0,048]}\end{array}$ & $\begin{array}{c}\text { ref. } \\
{[0,049]}\end{array}$ & $\begin{array}{c}\text { ref. } \\
{[0,048]}\end{array}$ \\
\hline 4. рабочие & $\begin{array}{c}\mathbf{- 0 , 1 7 6 * *} \\
{[0,034]}\end{array}$ & $\begin{array}{c}-0,087 \\
{[0,032]}\end{array}$ & $\begin{array}{c}\mathbf{- 0 , 1 8 7 * *} \\
{[0,034]}\end{array}$ & $\begin{array}{c}-0,082 \\
{[0,032]}\end{array}$ \\
\hline 5. менеджеры/администраторы & $\begin{array}{c}-0,017 \\
{[0,034]}\end{array}$ & $\begin{array}{c}-\mathbf{0 , 1 9 0 * *} \\
{[0,034]}\end{array}$ & $\begin{array}{c}-0,022 \\
{[0,034]}\end{array}$ & $\begin{array}{c}-\mathbf{0 , 1 8 8 * *} \\
{[0,034]}\end{array}$ \\
\hline 6. клерки & $\begin{array}{c}-0,057 \\
{[0,057]}\end{array}$ & $\begin{array}{c}-0,098 \\
{[0,034]}\end{array}$ & $\begin{array}{c}-0,063 \\
{[0,057]}\end{array}$ & $\begin{array}{c}-0,096 \\
{[0,054]}\end{array}$ \\
\hline 7. социокультурные (полу)профессионалы & $\begin{array}{l}-0,061 \\
{[0,042]}\end{array}$ & $\begin{array}{c}-\mathbf{0 , 1 8 3} * * \\
{[0,042]}\end{array}$ & $\begin{array}{c}-0,091 \\
{[0,042]}\end{array}$ & $\begin{array}{c}\mathbf{- 0 , 1 6 9 * *} \\
{[0,042]}\end{array}$ \\
\hline 8. работники сферы услуг & $\begin{array}{c}\mathbf{- 0 , 1 4 2 *} \\
{[0,034]}\end{array}$ & $\begin{array}{c}-0,064 \\
{[0,032]}\end{array}$ & $\begin{array}{l}\mathbf{- 0 , 1 5 8 *} \\
{[0,034]}\end{array}$ & $\begin{array}{c}-0,056 \\
{[0,032]}\end{array}$ \\
\hline Собственники бизнеса & $\begin{array}{c}0,102 \\
(0,047)^{*}\end{array}$ & $\begin{array}{c}0,000 \\
(0,047)\end{array}$ & $\begin{array}{c}0,095 \\
(0,047)^{*}\end{array}$ & $\begin{array}{c}0,003 \\
(0,047)\end{array}$ \\
\hline Возраст, лет & $\begin{array}{c}-0,004 \\
(0,002)^{*}\end{array}$ & $\begin{array}{l}-0,003 \\
(0,002)\end{array}$ & $\begin{array}{c}-\mathbf{0 , 0 0 4} \\
(\mathbf{0 , 0 0 2})^{*}\end{array}$ & $\begin{array}{l}-0,003 \\
(0,002)\end{array}$ \\
\hline Партнер/супруг(а) & $\begin{array}{c}0,014 \\
(0,034)\end{array}$ & $\begin{array}{c}0,031 \\
(0,033)\end{array}$ & $\begin{array}{c}0,008 \\
(0,034)\end{array}$ & $\begin{array}{c}0,034 \\
(0,033)\end{array}$ \\
\hline Женский пол & $\begin{array}{c}-0,078 \\
(0,033) *\end{array}$ & $\begin{array}{l}-0,017 \\
(0,032)\end{array}$ & $\begin{array}{c}-0,066 \\
(0,033)^{*}\end{array}$ & $\begin{array}{c}-0,024 \\
(0,032)\end{array}$ \\
\hline Дети & $\begin{array}{c}0,014 \\
(0,031)\end{array}$ & $\begin{array}{l}-0,046 \\
(0,031)\end{array}$ & $\begin{array}{c}0,017 \\
(0,031)\end{array}$ & $\begin{array}{l}-0,049 \\
(0,031)\end{array}$ \\
\hline Логарифм дохода & $\begin{array}{c}0,036 \\
(0,024)\end{array}$ & $\begin{array}{l}-0,020 \\
(0,024)\end{array}$ & $\begin{array}{c}0,034 \\
(0,024)\end{array}$ & $\begin{array}{l}-0,018 \\
(0,024)\end{array}$ \\
\hline Субъективное богатство & $\begin{array}{c}0,004 \\
(0,013)\end{array}$ & $\begin{array}{c}-0,037 \\
(0,013) * *\end{array}$ & $\begin{array}{l}-0,006 \\
(0,013)\end{array}$ & $\begin{array}{c}-0,031 \\
(0,013)^{*}\end{array}$ \\
\hline Субъективная власть & $\begin{array}{c}0,043 \\
(0,012)^{* * *}\end{array}$ & $\begin{array}{c}-0,076 \\
(0,012)^{* * *}\end{array}$ & $\begin{array}{c}0,039 \\
(0,012)^{* *}\end{array}$ & $\begin{array}{c}-0,074 \\
(0,012)^{* * *}\end{array}$ \\
\hline Субъективный престиж & $\begin{array}{c}-0,023 \\
(0,011)^{*}\end{array}$ & $\begin{array}{c}0,018 \\
(0,010)\end{array}$ & $\begin{array}{c}-0,024 \\
(0,011)^{*}\end{array}$ & $\begin{array}{c}0,018 \\
(0,010)\end{array}$ \\
\hline Страх, что не будет денег & & & $\begin{array}{c}-0,036 \\
(0,013)^{* *}\end{array}$ & $\begin{array}{c}0,026 \\
(0,013)^{*}\end{array}$ \\
\hline
\end{tabular}




\begin{tabular}{|c|c|c|c|c|}
\hline \multicolumn{5}{|l|}{ Занятость и трудовая уязвимость } \\
\hline работает и не боится потерять работу & \multirow{2}{*}{ ref. } & \multirow{2}{*}{ ref. } & $\begin{array}{c}\text { ref. } \\
{[0,022]}\end{array}$ & $\begin{array}{c}\text { ref. } \\
{[0,022]}\end{array}$ \\
\hline боится потерять работу & & & $\begin{array}{c}\mathbf{- 0 , 1 7 6 * * *} \\
{[0,030]}\end{array}$ & $\begin{array}{l}\mathbf{0 , 0 7 5} \\
{[0,030]}\end{array}$ \\
\hline не работает & $\begin{array}{c}-0,042 \\
(0,036)\end{array}$ & $\begin{array}{c}0,018 \\
(0,036)\end{array}$ & $\begin{array}{c}-\mathbf{- 0 , 1 0 3} * * \\
{[0,031]}\end{array}$ & $\begin{array}{c}0,044 \\
{[0,031]}\end{array}$ \\
\hline $\mathrm{R}^{2}$ & 0,024 & 0,043 & 0,033 & 0,045 \\
\hline
\end{tabular}

Примечание: ref. - категория сравнения. В круглых скобках указаны стандартные ошибки, в квадратных скобках - квазистандартные ошибки: ***p $<0.001,{ }^{* *} \mathrm{p}<0.01,{ }^{*} \mathrm{p}<0.05$.
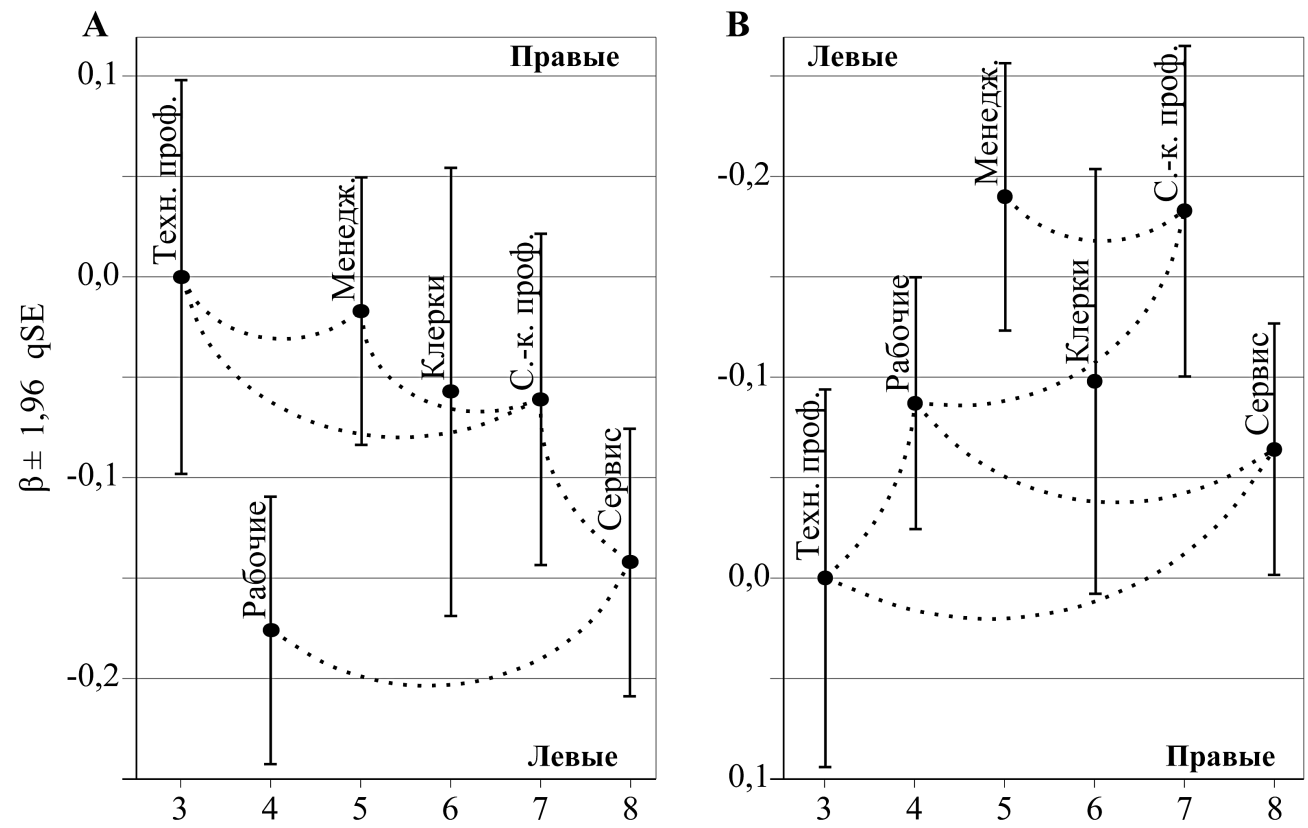

Рисунок 2. Коэффициенты классов Оеща в модели с зависимой переменной: (А) экономический консерватизм, (В) социальный консерватизм

Планки погрешностей отражают 95\%-й доверительный интервал. Категории, не имеющие значимых различий, соединены точечными кривыми. «Клерки» не имеют значимых различий ни с одним классом ни в одной из моделей, поэтому, чтобы не загромождать рисунок, кривые, соединяющие «клерков» с прочими классами, не изображены. На рисунке шкалы политических предпочтений на панелях А и В инвертированы относительно друг друга.

«Клерки» - самый малочисленный и, по всей видимости, гетерогенный класс в нашей выборке; эта категория не имеет значимых различий ни с одной другой. Положение остальных классов демонстрирует значимость противопоставления (полу)профессионалов и непрофессионалов: так, «менеджеры» при анализе обеих форм консерватизма значимо отличаются от «рабочих» и «работников сервиса». 
Результаты согласуются с полученными ранее на данных стран Западной Европы ${ }^{7}$ [Kitschelt, Rehm 2014; Коротаев, Гасюкова 2019]: занимающие верхнее положение в профессиональной иерархии (особенно, когда имеют работу организационной направленности) менее нуждаются в государственном экономическом содействии и более толерантно по сравнению с другими категориями работников относятся к мигрантам.

Наиболее интересна динамика «технических (полу)профессионалов»: по оси ЭК они занимают ту же позицию, что и прочие (полу)профессионалы, тогда как на оси СК они рядом с «рабочими» и «работниками сервиса». Если за негативным отношением низкоквалифицированных работников к мигрантам, возможно, стоит опасение потерять работу, то нетолерантность технических профессионалов не может быть объяснена логикой их труда и на текущий момент требует дальнейшего изучения в связи с неоднозначными выводами авторов по этому вопросу [Kitschelt, Rehm 2014; Oesch, Rennwald 2018]. В моделях ЭК собственники бизнеса демонстрируют правые ориентации, что соответствует зависимостям, полученным на данных западноевропейских государств [Oesch, Rennwald 2018].

Не обнаружено значимости в отношении наличия высшего образования респондентов, что, скорее, говорит о слабой дифференцирующей силе высшего образования в России. Поэтому в модели также были включены переменные о знании иностранного языка, продемонстрировавшие положительную связь с толерантным отношением респондентов к мигрантам, что также согласуется с общей тенденцией - образованные более лояльны к мигрантам.

Жители ПГТ и сел менее толерантны к приезжим мигрантам. Противоположные результаты были получены в работе под руководством М.Ф. Черныша, рассчитанные авторами индексы межэтнической напряженности оказались выше в крупных населенных пунктах [Черныш 2016, с. 14-16]. Однако с нашими результатами согласуются выводы исследования В.И. Мукомеля об интолерантных установках россиян [Мукомель 2017].

Неожиданным результатом может показаться отсутствие значимого влияния дохода как на экономический, так и на социальный консерватизм, при этом субъективное богатство значимо как предиктор СК. Допуская существование коллинеарности между фактическим доходом и самооценкой материального благополучия, мы повторили анализ без самооценки (не представлен), однако доход остался незначим. Более того, даже исключение всех самооценок из модели не делает доход значимым. Впрочем, в предшествующих исследованиях также не было обнаружено значимой связи между доходом и политическими предпочтениями россиян на фоне сильной значимости эффекта дохода у жителей Западной Европы [Коротаев, Гасюкова 2019]. Можно указать лишь на несовершенство выбранного подхода к стандартизации дохода и более сложного характера его пространственной гетерогенности.

При этом ряд субъективных оценок своего положения оказался устойчиво значим. Высокие показатели власти и уважения связаны с меньшим СК. В отношении оси ЭК эффекты власти и уважения разнонаправлены: власть ожидаемо связана с правыми ориентациями, тогда как уважение - левыми, что куда менее ожидаемо. Анализ корреляций показателей социального престижа с другими пере-

7 Предубежденность против мигрантов работников сервиса и рабочих также была получена на данных стран Восточной Европы (без России) [Коротаев, Гасюкова 2019]. 
менными продемонстрировал тесную связь уважения с оценкой индивидом своего профессионального мастерства (значение корреляции 0,47 ), т. е. наиболее уважаемые члены общества высоко оценивают свои профессиональные качества, и, возможно, из-за экономической недооцененности их профессионализма (статусной неконсистентности) они тяготеют к левым идеям и склонны выступать за политику перераспределения.

Перейдем к рассмотрению показателей уязвимости. Модель 2, отличающаяся от модели 1 введением в число предикторов субъективных показателей уязвимости, демонстрирует значимость страха потерять работу и не иметь денег в ближайшем году. Страх потерять работу оказывает даже большее влияние на политические ориентации, чем отсутствие работы (впрочем, различие между не имеющими работы и боящимися незначимо). Направление эффектов соответствует гипотезе 3 , т. е. может быть объяснено психологическими механизмами. Существенно то, что утилитарный интерес (гипотеза 2), хотя и не противоречит полученным данным, но и не объясняет их полностью. В этом плане эффект субъективных показателей уязвимости можно противопоставить эффекту отсутствия работы (по шкале СК отсутствие работы незначимо, по шкале ЭК - содействует левой ориентации), который хорошо объясняется с точки зрения утилитарного интереса.

Что касается эффекта нестабильности занятости (модель 3, приложение 4 на сайте журнала), то он оказался незначим. Предполагая, что воздействие оказывает лишь продолжительная нестабильность, мы рассмотрели модель 4 (см. приложение 4 на сайте журнала), где в качестве независимой переменной введен непрерывный стаж нестабильности от нуля до трех лет, однако коэффициенты при нестабильности занятости остались незначимы. С целью избежать относительно малочисленных категорий (меньше 200 респондентов) также была рассмотрена модель, в которой стаж нестабильности мог принимать только три значения: «нет нестабильности», «1 год», «не меньше двух лет» (не представлено), - однако коэффициенты при категориях нестабильности остались незначимы. Допуская, что эффект нестабильности может различаться для представителей различных социальных групп, мы рассмотрели интеракции переменной нестабильности с типом населенного пункта, наличием высшего образования и дихотомической переменной, маркирующей принадлежность респондента к (полу)профессионалам (классы 3, 5, 7), тем не менее значимые эффекты также не были выявлены (не представлено).

\section{Обсуждение и заключение}

В данной статье на основе трех конкурирующих механизмов: социализации, утилитарного интереса и психологических процессов - были рассмотрены факторы, влияющие на политические предпочтения. Основное внимание было уделено показателям уязвимости, исследование которых имеет, с одной стороны, практическую актуальность в контексте дискуссии о роли уязвимости как фактора политической мобилизации [Стэндинг 2014], с другой - теоретико-методологическую, поскольку потенциально ставит под сомнение валидность традиционных подходов рассмотрения политических воззрений граждан. Было получено, что, хотя механизм социа- 
лизации способен убедительно объяснить ряд полученных закономерностей связи показателей социального положения и политических предпочтений, он не является достаточным (гипотеза 1 не может быть принята) при моделировании идеологической позиции граждан, находящихся в состоянии экономической уязвимости.

Психологический подход выглядит многообещающим, полученные результаты соответствуют растущему в литературе признанию важности рассмотрения психологических предикторов идеологической позиции. Потенциальная значимость психологических факторов не отрицает возможную роль утилитарного интереса, но указывает на недостаточность одного лишь его для описания полученных зависимостей.

В качестве одного из показателей уязвимости была использована трудовая нестабильность. Нам не удалось выявить влияние нестабильности на политические предпочтения, при этом, рассмотрев интеракции переменной нестабильности с профессией, типом населенного пункта и образованием, мы учли возможность того, что уязвимыми являются лишь низкостатусные нестабильно занятые работники, тогда как для профессионалов частая смена работодателя может быть карьерной стратегией (т. н. портфолийная карьера) [Throsby, Zednik 2011]. Поиск причин этого результата приводит нас к обсуждению ограничений исследования.

Очевидным ограничением является косвенность использованной меры нестабильности; в действительности у нас нет надежных данных, указывающих на частоту смены работы респондентом. Помимо этого, большое количество пропущенных данных ведет к увеличению дисперсии регрессионных коэффициентов, что также может быть причиной отсутствия значимости. Другое ограничение связано с используемыми для получения пространства политических предпочтений переменными. Для анализа был отобран значительно более узкий набор вопросов, чем тот, который применялся во многих цитированных исследованиях. Кроме того, экономическая ось была построена на вопросах, которые лишь с учетом ряда допущений соответствуют конвенциональной мере экономического консерватизма.

Другой ряд ограничений связан с тем, что мы никак не измеряли психологические показатели (например RWA), являющиеся медиатором воздействия уязвимости на политические предпочтения. Помимо этого, психологическая модель была построена вокруг авторитаризма; иные психологические параметры, связанные с идеологией (напр., SDO) и потенциально чувствительные к уязвимости (напр., [Onraet et al. 2014; Shaffer, Duckitt 2013]), не получили развития в данной статье в силу ограниченности данных и социологической направленности исследования. Кроме того, мы не рассматривали возможность того, что RWA, как относительно устойчивая во времени предрасположенность, может сама оказывать влияние на восприятие угроз (напр., [Onraet et al. 2014]). Следовательно, субъективно уязвимыми оказываются не только те, кто находится в определенной ситуации (из чего мы исходили), но также и те, кто психологически предрасположен воспринимать обстоятельства как угрожающие. Наконец, нельзя полностью исключить наличие пропущенной переменной, связанной как с вероятностью трудовой уязвимости, так и с политическими предпочтениями. В частности, можно ожидать, что тип населенного пункта не исчерпывает пространственную гетерогенность России. Так, жители депрессивных регионов и моногородов могут иметь большой шанс попасть в уязвимое положение, но их установки будут уже отражением социализации в данной среде. Все вышесказанное приводит к заключению, что «психологиче- 
ская» линия анализа носит лишь предварительный характер. Последнее замечание состоит в том, что используемые нами данные были собраны в период с октября 2015-го по январь 2016 г., когда еще сохранялся эффект «крымских событий» 2014 г. Поддержкой пользовался взгляд на Россию, как противостоящую Западу/ США, популярны были изоляционистские настроения (в т. ч. в контексте санкций), охранительные блага [Карачаровский, Шкаратан 2020]. Это потенциально могло повлиять на наши результаты, а, следовательно, их проверка на более свежих данных представляется разумным направлением для последующих исследований.

\section{Список источников}

Аникин В.А., Лежнина Ю.П., Мареева С.В., Слободенюк Е.Д. (2019) Запросы россиян на содействие государства: социальное инвестирование или социальная поддержка?// Мониторинг общественного мнения: экономические и социальные перемены. № 3 . C. 345-366. DOI: 10.14515/monitoring.2019.3.19

Безработица в России и зарубежных странах в условиях кризиса (2015) // Аналитический центр при правительстве Российской Федерации // https://ac.gov.ru/archive/files/publication/a/4987.pdf, дата обращения 31.10.2021.

Бикбов А.Т. (2014) Грамматика порядка: Историческая социология понятий, которые меняют нашу реальность. М.: ВШЭ.

Бурдье П. (1993) Политические позиции и культурный капитал // Бурдье П. Социология политики. М.: Socio-Logos. C. 98-162.

Бызов Л.Г. (2014) Новое консервативное большинство как социально-политический феномен // Мир России. Социология. Этнология. Т. 23. № 4. С. 6-34.

Галкин А.А. (1998) Тенденции изменения социальной структуры // Социологические исследования. № 10. С. 85-91.

Гельман В.Я. (2020) «Либералы» versus «демократы»: идейные траектории постсоветской трансформации в России // Мир России. Т. 29. №. 1. С. 53-79. DOI: $10.17323 / 1811-038 X-2020-29-1-53-79$

Гимпельсон В.Е., Ощепков А.Ю. (2011) Уровень и страх безработицы: есть ли между ними связь? // Экономический журнал Высшей школы экономики. № 3(15). С. 277-314.

Карабчук Т.С. (2008) Непостоянная занятость на российском рынке труда: экономико-социологический анализ. Автореф. канд. экон. наук. М.: ВШЭ.

Карачаровский В.В., Шкаратан О.И. (2020) Когда благо благу рознь: две грани социального выбора // Социологические исследования. № 3. С. 27-39. DOI: $10.31857 / \mathrm{S} 013216250008810-4$

Кордонский С.Г. (2008) Сословная структура постсоветской России (часть II) // Мир России. Социология. Этнология. Т. 17. № 4. С. 3-36.

Коротаев С.А., Гасюкова Е.Н. (2019) Социальные различия и политическое участие: медиирующая роль идеологических предпочтений // Экономическая социология. Т. 20. № 3. C. 99-135.

Мукомель В.И. (2017) Ксенофобии на Юге России: носители интолерантных установок // Гуманитарий Юга России. Т. 6. № 5. C. 29-47. DOI: 10.23683/2227-8656.2017.5.2

Стэндинг Г. (2014) Прекариат: новый опасный класс. M.: Ad Marginem.

Тощенко Ж.Т. (2017) От пролетариата к прекариату (о возникновении нового класса) // Журнал Белорусского государственного университета. Социология. № 3. С. 95-101.

Черныш М.Ф. (ред.) (2016) Социокультурные и социоструктурные факторы межэтнической напряженности в регионах Российской Федерации: результаты исследования. М.: ИС РАН.

Altemeyer B. (1998) The Other "Authoritarian Personality" // Advances in Experimental Social Psychology (ed. Zanna M.P.), vol. 30, New York: Academic Press, pp. 47-92. 
Asbrock F., Fritsche I. (2013) Authoritarian Reactions to Terrorist Threat: Who Is Being Threatened, the Me or the We? // International Journal of Psychology, vol. 48, no 1, pp. 35-49. DOI: 10.1080/00207594.2012.695075

Aspelund A., Lindeman M., Verkasalo M. (2013) Political Conservatism and Left-Right Orientation in 28 Eastern and Western European Countries // Political Psychology, vol. 34, no 3, pp. 409-417. DOI: $10.1111 /$ pops. 12000

Bonanno G.A., Jost J.T. (2006) Conservative Shift among High-Exposure Survivors of the September $11^{\text {th }}$ Terrorist Attacks // Basic and Applied Social Psychology, vol. 28, no 4, pp. 311-323. DOI: 10.1207/s15324834basp2804_4

Bornschier S. (2010) The New Cultural Divide and the Two-Dimensional Political Space in Western Europe // West European Politics, vol. 33, no 3, pp. 419-444. DOI: $10.1080 / 01402381003654387$

Brooks C., Svallfors S. (2010) Why Does Class Matter? Policy Attitudes, Mechanisms, and the Case of the Nordic Countries // Research in Social Stratification and Mobility, vol. 28, no 2, pp. 199-213. DOI: $10.1016 /$ j.rssm.2010.01.003

Brown-Iannuzzi J.L., Lundberg K.B., Kay A.C., Payne B.K. (2015) Subjective Status Shapes Political Preferences // Psychological Science, vol. 26, no 1, pp. 15-26. DOI: $10.1177 / 0956797614553947$

Chan T.W., Goldthorpe J.H. (2007) Class and Status: The Conceptual Distinction and Its Empirical Relevance // American Sociological Review, vol. 72, no 4, pp. 512-532. DOI: $10.1177 / 000312240707200402$

Clark A., D’Angelo E. (2010) Upward Social Mobility, Well-Being and Political Preferences: Evidence from the BHPS. Working Papers. No. 338, Universita Politecnica delle Marche (I), Dipartimento di Economia.

Cusack T., Iversen T., Rehm P. (2006) Risks at Work: The Demand and Supply Sides of Government Redistribution // Oxford Review of Economic Policy, vol. 22, no 3, pp. 365-389. DOI: 10.1093/oxrep/grj022

Dalton R.J. (2013) The Social Bases of Party Support // Dalton R.J. Citizen Politics: Public Opinion and Political Parties in Advanced Industrial Democracies, Chatham, NJ: Chatham House, pp. 155-182.

Duckitt J., Wagner C., Du Plessis I., Birum I. (2002) The Psychological Bases of Ideology and Prejudice: Testing a Dual Process Model // Journal of Personality and Social Psychology, vol. 83, no 1, pp. 75-93. DOI: 10.1037//0022-3514.83.1.75

Duriez B., van Hiel A., Kossowska M. (2005) Authoritarianism and Social Dominance in Western and Eastern Europe: The Importance of the Sociopolitical Context and of Political Interest and Involvement // Political Psychology, vol. 26, no 2, pp. 299-320. DOI: $10.1111 /$ j.1467-9221.2005.00419.x

Emmenegger P., Marx P., Schraff D. (2015) Labour Market Disadvantage, Political Orientations and Voting: How Adverse Labour Market Experiences Translate into Electoral Behaviour // Socio-Economic Review, vol. 13, no 2, pp. 189-213. DOI: 10.1093/ser/mwv003

Evans G. (1997) Class Inequality and the Formation of Political Interests in Eastern Europe // European Journal of Sociology, vol. 38, pp. 207-234. DOI: 10.1017/S0003975600006949

Evans G., Heath A., Lalljee M. (1996) Measuring Left-Right and Libertarian-Authoritarian Values in the British Electorate // British Journal of Sociology, vol. 47, no 1, pp. 93-112. DOI: $10.2307 / 591118$

Feldman S. (2013) Comments on: Authoritarianism in Social Context: The Role of Threat // International Journal of Psychology, vol. 48, no 1, pp. 55-59. DOI: $10.1080 / 00207594.2012 .742196$

Feldman S., Johnston C. (2014) Understanding the Determinants of Political Ideology: Implications of Structural Complexity // Political Psychology, vol. 35, no 3, pp. 337-358. DOI: $10.1111 /$ pops. 12055

Firth D. (2003) Overcoming the Reference Category Problem in the Presentation of Statistical Models // Sociological Methodology, vol. 33, no 1, pp. 1-18. DOI: $10.1111 / \mathrm{j} .0081-1750.2003 . t 01-1-00125 . \mathrm{x}$ 
Gadarian S.K. (2010) The Politics of Threat: How Terrorism News Shapes Foreign Policy Attitudes // The Journal of Politics, vol. 72, no 2, pp. 469-483. DOI: $10.1017 / \mathrm{S} 0022381609990910$

Glauber R. (2013) Wanting More but Working Less: Involutary Part-Time Employment and Economic Vulnerability // Carsey Institute. Issue Brief. No. 64, Durham, NH: Carsey Institute.

Grigoryev D., Batkhina A., Van De Vijver F., Berry J.W. (2020) Towards an Integration of Models of Discrimination of Immigrants: From Ultimate (Functional) to Proximate (Sociofunctional) Explanations // Journal of International Migration and Integration, vol. 21, pp. 667-691. DOI: 10.1007/s12134-019-00677-w

Guillaud E. (2013) Preferences for Redistribution: An Empirical Analysis over 33 Countries // The Journal of Economic Inequality, vol. 11, no 1, pp. 57-78. DOI: $10.1007 / \mathrm{s} 10888-011-9205-0$

Harrits G.S., Prieur A., Rosenlund L., Skjott-Larsen J. (2010) Class and Politics in Denmark: Are Both Old and New Politics Structured by Class? // Scandinavian Political Studies, vol. 33, no 1, pp. 1-27. DOI: 10.1111/j.1467-9477.2008.00232.x

Janoff-Bulman R., Carnes N.C. (2016) Social Justice and Social Order: Binding Moralities across the Political Spectrum // PloS One, vol. 11, no 3, pp. 1-18. DOI: 10.1371/journal.pone.0152479

Jost J.T., Federico C.M., Napier J.L. (2009) Political Ideology: Its Structure, Functions, and Elective Affinities // Annual Review of Psychology, vol. 60, no 1, pp. 307-337. DOI: 10.1146/annurev.psych.60.110707.163600

Jost J.T., Glaser J., Kruglanski A.W., Sulloway F.J. (2003) Political Conservatism as Motivated Social Cognition // Psychological Bulletin, vol. 129, no 3, 339-375. DOI: 10.1037/0033-2909.129.3.339

Kitschelt H., Rehm P. (2014) Occupations as a Site of Political Preference Formation// Comparative Political Studies, vol. 47, no 12, pp. 1670-1706. DOI: 10.1177/0010414013516066

Kriesi H., Grande E., Lachat R., Dolezal M., Bornschier S., Frey T. (2006) Globalization and the Transformation of the National Political Space: Six European Countries Compared // European Journal of Political Research, vol. 45, no 6, pp. 921-956. DOI: 10.5167/uzh-2978

Lamprianou I. (2013) Contemporary Political Participation Research: A Critical Assessment // Democracy in Transition (ed. Demetriou K.N.), Berlin; Heidelberg: Springer Science \& Business Media, pp. 21-42.

Latimer J., Munro R. (2015) Uprooting Class? Culture, World-Making and Reform // The Sociological Review, vol. 63, no 2, pp. 415-432. DOI: 10.1111/1467-954X.12289

Mackenzie C. (2014) The Importance of Relational Autonomy and Capabilities for an Ethics of Vulnerability // Vulnerability: New Essays in Ethics and Feminist Philosophy (eds. Mackenzie C., Rogers W., Dodds S.), New York: Oxford University Press, pp. 33-59.

Marks G., Hooghe L., Nelson M., Edwards E. (2006) Party Competition and European Integration in the East and West: Different Structure, Same Causality // Comparative Political Studies, vol. 39, no 2, pp. 155-175. DOI: 10.1177/0010414005281932

Mayda A.M. (2006) Who Is Against Immigration? A Cross-Country Investigation of Individual Attitudes toward Immigrants // The Review of Economics and Statistics, vol. 88, no 3, pp. 510-530.

McFarland S.G., Ageyev V.S., Djintcharadze N. (1996) Russian Authoritarianism Two Years after Communism // Personality and Social Psychology Bulletin, vol. 22, no 2, pp. 210-217. DOI: $10.1177 / 0146167296222010$

Migliavacca M. (2010) Social Vulnerability Approach and the Transformations in the Labor Market. The Impact of Instable Jobs on Household Structures // Inequality beyond Globalization: Economic Changes, Social Transformations, and the Dynamics of Inequality (ed. Sute C.), Münste: Lit Verlag, pp. 1-21.

Mochmann I.C., El-Menouar Y. (2005) Lifestyle Groups, Social Milieus and Party Preference in Eastern and Western Germany: Theoretical Considerations and Empirical Results // German Politics, vol. 14, no 4, pp. 417-437. DOI: 10.1080/09644000500340594 
Oesch D. (2006) Coming to Grips with a Changing Class Structure // International Sociology, vol. 21, no 2, pp. 263-288. DOI: 10.1177/0268580906061379

Oesch D., Rennwald L. (2018) Electoral Competition in Europe's New Tripolar Political Space: Class Voting for the Left, Centre-Right and Radical Right // European Journal of Political Research, vol. 57, no 4, pp. 783-807. DOI: 10.1111/1475-6765.12259

Onraet E., Dhont K., Van Hiel A. (2014) The Relationships between Internal and External Threats and Right-wing Attitudes: A Three-wave Longitudinal Study // Personality and Social Psychology Bulletin, vol. 40, no 6, pp. 712-725. DOI: 10.1177/0146167214524256

Owens L.A., Pedulla D.S. (2014) Material Welfare and Changing Political Preferences: The Case of Support for Redistributive Social Policies // Social Forces, vol. 92, no 3, pp. 1087-1113. DOI: $10.1093 / \mathrm{sf} / \mathrm{sot} 101$

Oxley D.R., Smith K.B., Alford J.R., Hibbing M.V., Miller J.L., Scalora M., Hatemi P.K., Hibbing J.R. (2008) Political Attitudes Vary with Physiological Traits // Science, vol. 321, no 5896, pp. 1667-1670. DOI: 10.1126/science.1157627

Paas T., Demidova O. (2014) What Explains People's Attitudes towards Immigrants? A Comparative Study of Estonia and Russia // The University of Tartu Faculty of Economics and Business Administration. Working Paper. No. 94.

Pratto F., Sidanius J., Stallworth L., Malle B. (1994) Social Dominance Orientation: A Personality Variable Predicting Social and Political Attitudes // Journal of Personality and Social Psychology, vol. 67, no 4, pp. 741-763. DOI: 10.1037//0022-3514.67.4.741

Shaffer B., Duckitt J. (2013) The Dimensional Structure of People's Fears, Threats, and Concerns and Their Relationship with Right-Wing Authoritarianism and Social Dominance Orientation // International Journal of Psychology, vol. 48, no 1, pp. 6-17. DOI: $10.1080 / 00207594.2012 .696651$

Smyth R. (2012) Political Preferences and Party Development in Post-Communist States // Demokratizatsiya, vol. 20, no 2, pp. 113-132.

Stubager R. (2008) Education Effects on Authoritarian-Libertarian Values: A Question of Socialization // The British Journal of Sociology, vol. 59, no 2, pp. 327-350. DOI: 10.1111/j.1468-4446.2008.00196.x

Throsby D., Zednik A. (2011) Multiple Job-holding and Artistic Careers: Some Empirical Evidence // Cultural Trends, vol. 20, no 1, pp. 9-24. DOI: 10.1080/09548963.2011.540809

Torche F., Lopez-Calva L.F. (2013) Stability and Vulnerability of the Latin American Middle Class // Oxford Development Studies, vol. 41, no 4, pp. 409-435. DOI: 10.1080/13600818.2013.831060

Vasilopoulos P., Lachat R. (2018) Authoritarianism and Political Choice in France // Acta Politica, vol. 53, no 4, pp. 612-634. DOI: 10.1057/s41269-017-0066-9

Visser M., Lubbers M., Kraaykamp G., Jaspers E. (2014) Support for Radical Left Ideologies in Europe // European Journal of Political Research, vol. 53, no 3, pp. 541-558. DOI: $10.1111 / 1475-6765.12048$

Vives A., Amable M., Ferrer M., Moncada S., Lloren C., Muntaner C., Benavides F., Benach J. (2013) Employment Precariousness and Poor Mental Health: Evidence from Spain on a New Social Determinant of Health // Journal of Environmental and Public Health, vol. 2013, pp. 1-10. DOI: 10.1155/2013/978656

Wheatley J. (2015) Identifying Latent Policy Dimensions from Public Opinion Data: An Inductive Approach // Journal of Elections, Public Opinion \& Parties, vol. 25, no 2, pp. 215-233. DOI: $10.1080 / 17457289.2014 .985222$

Wilson K. (2012) How Russians View Electoral Fairness: A Qualitative Analysis // Europe-Asia Studies, vol. 64, no 1, pp. 145-168. DOI: 10.1080/09668136.2012.635485

Zuckerman A.S., Kotler-Berkowitz L.A., Swaine L.A. (1998) Anchoring Political Preferences: The Structural Bases of Stable Electoral Decisions and Political Attitudes in Britain // European Journal of Political Research, vol. 33, no 3, pp. 285-321. DOI: $10.1111 / 1475-6765.00384$ 


\title{
S.A. KOROTAEV*, E.N. GASIUKOVA**
}

\begin{abstract}
*Sergey A. Korotaev - Researcher, HSE University, Moscow, Russian Federation, skorotaev@hse.ru, https://orcid.org/0000-0002-7038-2759

**Elena N. Gasiukova - Junior Researcher, HSE University, Moscow, Russian Federation, egasyukova@hse.ru, https://orcid.org/0000-0001-6938-5218

Citation: Korotaev S.A., Gasiukova E.N. (2022) Political Preferences: the Effect of Economic Vulnerability. Mir Rossii, vol. 31, no 1, pp. 138-161 (in Russian). DOI: $10.17323 / 1811-038 X-2022-31-1-138-161$
\end{abstract}

\begin{abstract}
This article investigates the factors influencing political preferences through three competing theoretical approaches. How political views form can be explained through socialization (political preferences reflect ideas about what is right and proper, absorbed in the process of socialization), a utilitarian view (political preferences as a reflection of the pragmatic interests of individuals), psychological mechanisms (reaction to uncertainty and threat). Using data from the Russian Logitudinal Monitoring Survey of HSE University in 2015, we seek to understand which approach best describes the political preferences of vulnerable Russians. Several indicators were used as a measure of respondents' vulnerability: employment instability, fear of losing jobs, and the inability to secure their lives in the short-term future. Focusing on economically vulnerable respondents makes it possible to identify those social preferences that can be associated with the concept of protective benefits responsible for maintaining and strengthening social order. The political space we study is based on two axes derived from factor analysis and includes preferences in the economic sphere (role of the state and the private sector) and in the social sphere (attitude towards migrants). Our analysis reveals the importance of the subjective perception of vulnerability in employment and material well-being. The vulnerable respondents, who are afraid to lose their jobs, favor left-wing economic policies, and are less tolerant of migrants. Employment instability as such does not have a significant impact on political perceptions. In conclusion, we also discuss the limitations of our research.
\end{abstract}

Keywords: political preferences, political ideology, political psychology, social structure, employment instability, pragmatic interest, socialization

\section{References}

Altemeyer B. (1998) The Other "Authoritarian Personality". Advances in Experimental Social Psychology (ed. Zanna M.P.), vol. 30, New York: Academic Press, pp. 47-92.

Anikin V., Lezhnina Y., Mareeva S., Slobodenyuk E. (2019) Russian Public Demand for State Assistance: Social Investment or Social Support? Monitorin of Public Opinion: Economic and Social Changes, no 3, pp. 345-366 (in Russian). DOI: $10.14515 /$ monitoring.2019.3.19

This work was supported by the Russian Science Foundation, grant № 16-18-10270.

The article was received in September 2020. 
Asbrock F., Fritsche I. (2013) Authoritarian Reactions to Terrorist Threat: Who Is Being Threatened, the Me or the We? International Journal of Psychology, vol. 48, no 1, pp. 35-49. DOI: 10.1080/00207594.2012.695075

Aspelund A., Lindeman M., Verkasalo M. (2013) Political Conservatism and Left-Right Orientation in 28 Eastern and Western European Countries. Political Psychology, vol. 34, no 3, pp. 409-417. DOI: 10.1111/pops. 12000

Bikbov A. (2014) Grammar of Order: Historical Sociology of Concepts that Change Our Reality, Moscow: HSE (in Russian).

Bonanno G.A., Jost J.T. (2006) Conservative Shift among High-Exposure Survivors of the September $11^{\text {th }}$ Terrorist Attacks. Basic and Applied Social Psychology, vol. 28, no 4, pp. 311-323. DOI: $10.1207 / \mathrm{s} 15324834$ basp2804 4

Bornschier S. (2010) The New Cultural Divide and the Two-Dimensional Political Space in Western Europe. West European Politics, vol.33, no 3,pp.419-444.DOI: 10.1080/01402381003654387

Bourdieu P. (1993) The Political Positions and Cultural Capital. Bourdieu P. The Sociology of Politics, Moscow: Socio-Logos, pp. 98-162 (in Russian).

Brooks C., Svallfors S. (2010) Why Does Class Matter? Policy Attitudes, Mechanisms, and the Case of the Nordic Countries. Research in Social Stratification and Mobility, vol. 28, no 2, pp. 199-213. DOI: 10.1016/j.rssm.2010.01.003

Brown-Iannuzzi J.L., Lundberg K.B., Kay A.C., Payne B.K. (2015) Subjective Status Shapes Political Preferences. Psychological Science, vol. 26, no 1, pp. 15-26. DOI: $10.1177 / 0956797614553947$

Byzov L. (2014) The New Conservative Majority as a Socio-Political Phenomenon. Mir Rossii, vol. 23, no 4, pp. 6-34 (in Russian).

Chan T.W., Goldthorpe J.H. (2007) Class and Status: The Conceptual Distinction and Its Empirical Relevance. American Sociological Review, vol. 72, no 4, pp. 512-532. DOI: $10.1177 / 000312240707200402$

Chernysh M. (ed.) (2016) Sociocultural and Sociostructural Factors of Inter-ethnic Tensions in the Regions of the Russian Federation: Results of the Survey, Moscow: IS RSA (in Russian).

Clark A., D'Angelo E. (2010) Upward Social Mobility, Well-Being and Political Preferences: Evidence from the BHPS. Working Papers. No. 338, Universita Politecnica delle Marche (I), Dipartimento di Economia.

Cusack T., Iversen T., Rehm P. (2006) Risks at Work: The Demand and Supply Sides of Government Redistribution. Oxford Review of Economic Policy, vol. 22, no 3, pp. 365-389. DOI: 10.1093/oxrep/grj022

Dalton R.J. (2013) The Social Bases of Party Support. Dalton R.J. Citizen Politics: Public Opinion and Political Parties in Advanced Industrial Democracies, Chatham, NJ: Chatham House, pp. 155-182.

Duckitt J., Wagner C., Du Plessis I., Birum I. (2002) The Psychological Bases of Ideology and Prejudice: Testing a Dual Process Model. Journal of Personality and Social Psychology, vol. 83, no 1, pp. 75-93. DOI: 10.1037//0022-3514.83.1.75

Duriez B., van Hiel A., Kossowska M. (2005) Authoritarianism and Social Dominance in Western and Eastern Europe: The Importance of the Sociopolitical Context and of Political Interest and Involvement. Political Psychology, vol. 26, no 2, pp. 299-320. DOI: $10.1111 / \mathrm{j} .1467-9221.2005 .00419 . x$

Emmenegger P., Marx P., Schraff D. (2015) Labour Market Disadvantage, Political Orientations and Voting: How Adverse Labour Market Experiences Translate into Electoral Behaviour. Socio-Economic Review, vol. 13, no 2, pp. 189-213. DOI: 10.1093/ser/mwv003

Evans G. (1997) Class Inequality and the Formation of Political Interests in Eastern Europe. European Journal of Sociology, vol. 38, pp. 207-234. DOI: 10.1017/S0003975600006949

Evans G., Heath A., Lalljee M. (1996) Measuring Left-Right and Libertarian-Authoritarian Values in the British Electorate. British Journal of Sociology, vol. 47, no 1, pp. 93-112. DOI: $10.2307 / 591118$

Feldman S. (2013) Comments on: Authoritarianism in Social Context: The Role of Threat. International Journal of Psychology, vol. 48, no 1, pp. 55-59. DOI: 10.1080/00207594.2012.742196 
Feldman S., Johnston C. (2014) Understanding the Determinants of Political Ideology: Implications of Structural Complexity. Political Psychology, vol. 35, no 3, pp. 337-358. DOI: $10.1111 /$ pops. 12055

Firth D. (2003) Overcoming the Reference Category Problem in the Presentation of Statistical Models. Sociological Methodology, vol. 33, no 1, pp. 1-18. DOI: 10.1111/j.0081-1750.2003. t01-1-00125.x

Gadarian S.K. (2010) The Politics of Threat: How Terrorism News Shapes Foreign Policy. The Journal of Politics, vol. 72, no 2, pp. 469-483. DOI: 10.1017/S0022381609990910

Galkin A. (1998) Trends in Social Structure Change. Sociological Studies, no 10, pp. 85-91 (in Russian).

Gimpel'son V., Oshchepkov A. (2011) Unemployment Rate and Fear: Is There a Link between Them? The HSE Economic Journal, vol. 15, no 3, pp. 277-314 (in Russian).

Gel'man V.Y. (2020) 'Liberals' versus 'Democrats': Ideational Trajectories of Russia's PostCommunist Transformation. Mir Rossii, vol. 29, no 1, pp. pp. 53-79 (in Russian). DOI: $10.17323 / 1811-038 X-2020-29-1-53-79$

Glauber R. (2013) Wanting More but Working Less: Involutary Part-Time Employment and Economic Vulnerability. Carsey Institute. Issue Brief. No. 64, Durham, NH: Carsey Institute.

Grigoryev D., Batkhina A., Van De Vijver F., Berry J.W. (2020) Towards an Integration of Models of Discrimination of Immigrants: From Ultimate (Functional) to Proximate (Sociofunctional) Explanations. Journal of International Migration and Integration, vol. 21, pp. 667-691. DOI: 10.1007/s12134-019-00677-w

Guillaud E. (2013) Preferences for Redistribution: An Empirical Analysis over 33 Countries. The Journal of Economic Inequality, vol. 11, no 1, pp. 57-78. DOI: 10.1007/s10888-011-9205-0

Harrits G.S., Prieur A., Rosenlund L., Skjott-Larsen J. (2010) Class and Politics in Denmark: Are Both Old and New Politics Structured by Class? Scandinavian Political Studies, vol. 33, no 1, pp. 1-27. DOI: 10.1111/j.1467-9477.2008.00232.x

Janoff-Bulman R., Carnes N.C. (2016) Social Justice and Social Order: Binding Moralities across the Political Spectrum. PloS One, vol. 11, no 3, pp. 1-18. DOI: 10.1371/journal.pone.0152479

Jost J.T., Federico C.M., Napier J.L. (2009) Political Ideology: Its Structure, Functions, and Elective Affinities. Annual Review of Psychology, vol. 60, no 1, pp. 307-337. DOI: 10.1146/annurev.psych.60.110707.163600

Jost J.T., Glaser J., Kruglanski A.W., Sulloway F.J. (2003) Political Conservatism as Motivated Social Cognition. Psychological Bulletin, vol. 129, no 3, pp. 339-375. DOI: 10.1037/0033-2909.129.3.339

Karabchuk T. (2008) Non-permanent Employment in the Russian Labor Market: An Economic and Sociological Analysis, Moscow: HSE (in Russian).

Karacharovskiy V., Shkaratan O. (2020) When the Good Is Divided: Two Facets of Social Choice. Sociological Studies, no 3, pp. 27-39 (in Russian). DOI: 10.31857/S013216250008810-4

Kitschelt H., Rehm P. (2014) Occupations as a Site of Political Preference Formation. Comparative Political Studies, vol. 47, no 12, pp. 1670-1706. DOI: 10.1177/0010414013516066

Kordonskiy S. (2008) Estate Structure of post-Soviet Russia (Part II). Mir Rossii, vol. 17, no 4, pp. 3-36 (in Russian).

Korotaev S., Gasiukova E. (2019) The Social Differences and Political Participation: The Mediating Role of Ideological Preferences. Ekonomicheskaya Sotsiologiya / Journal of Economic Sociology, vol. 20, no 3, pp. 99-135 (in Russian).

Kriesi H., Grande E., Lachat R., Dolezal M., Bornschier S., Frey T. (2006) Globalization and the Transformation of the National Political Space: Six European Countries Compared. European Journal of Political Research, vol. 45, no 6, pp. 921-956. DOI: 10.5167/uzh-2978

Lamprianou I. (2013) Contemporary Political Participation Research: A Critical Assessment. Democracy in Transition (ed. Demetriou K.N.), Berlin; Heidelberg: Springer Science \& Business Media, pp. 21-42.

Latimer J., Munro R. (2015) Uprooting Class? Culture, World-Making and Reform. The Sociological Review, vol. 63, no 2, pp. 415-432. DOI: 10.1111/1467-954X.12289

Mackenzie C. (2014) The Importance of Relational Autonomy and Capabilities for an Ethics of Vulnerability. Vulnerability: New Essays in Ethics and Feminist Philosophy (eds. Mackenzie C., Rogers W., Dodds S.), New York: Oxford University Press, pp. 33-59. 
Marks G., Hooghe L., Nelson M., Edwards E. (2006) Party Competition and European Integration in the East and West: Different Structure, Same Causality. Comparative Political Studies, vol. 39, no 2, pp. 155-175. DOI: 10.1177/0010414005281932

Mayda A.M. (2006) Who Is Against Immigration? A Cross-Country Investigation of Individual Attitudes toward Immigrants. The Review of Economics and Statistics, vol. 88, no 3, pp. 510-530.

McFarland S.G., Ageyev V.S., Djintcharadze N. (1996) Russian Authoritarianism Two Years after Communism. Personality and Social Psychology Bulletin, vol. 22, no 2, pp. 210-217. DOI: $10.1177 / 0146167296222010$

Migliavacca M. (2010) Social Vulnerability Approach and the Transformations in the Labor Market. The Impact of Instable Jobs on Household Structures. Inequality beyond Globalization: Economic Changes, Social Transformations, and the Dynamics of Inequality (ed. Sute C.), Münste: Lit Verlag, pp. 1-21.

Mochmann I.C., El-Menouar Y. (2005) Lifestyle Groups, Social Milieus and Party Preference in Eastern and Western Germany: Theoretical Considerations and Empirical Results. German Politics, vol. 14, no 4, pp. 417-437. DOI: 10.1080/09644000500340594

Mukomel V. (2017) Xenophobia in the South of Russia: Carriers of Intolerant Attitudes. Humanities of the South of Russia, vol. 6, no 5, pp. 29-47 (in Russian). DOI: $10.23683 / 2227-8656.2017 .5 .2$

Oesch D. (2006) Coming to Grips with a Changing Class Structure. International Sociology, vol. 21, no 2, pp. 263-288. DOI: 10.1177/0268580906061379

Oesch D., Rennwald L. (2018) Electoral Competition in Europe's New Tripolar Political Space: Class Voting for the Left, Centre-Right and Radical Right. European Journal of Political Research, vol. 57, no 4, pp. 783-807. DOI: 10.1111/1475-6765.12259

Onraet E., Dhont K., Van Hiel A. (2014) The Relationships between Internal and External Threats and Right-wing Attitudes: A Three-wave Longitudinal Study. Personality and Social Psychology Bulletin, vol. 40, no 6, pp. 712-725. DOI: 10.1177/0146167214524256

Owens L.A., Pedulla D.S. (2014) Material Welfare and Changing Political Preferences: The Case of Support for Redistributive Social Policies. Social Forces, vol. 92, no 3, pp. 1087-1113. DOI: $10.1093 / \mathrm{sf} /$ sot 101

Oxley D.R., Smith K.B., Alford J.R., Hibbing M.V., Miller J.L., Scalora M., Hatemi P.K., Hibbing J.R. (2008) Political Attitudes Vary with Physiological Traits. Science, vol. 321, no 5896, pp. 1667-1670. DOI: 10.1126/science.1157627

Paas T., Demidova O. (2014) What Explains People's Attitudes towards Immigrants? A Comparative Study of Estonia and Russia. The University of Tartu Faculty of Economics and Business Administration. Working Paper. No. 94.

Pratto F., Sidanius J., Stallworth L., Malle B. (1994) Social Dominance Orientation: A Personality Variable Predicting Social and Political Attitudes. Journal of Personality and Social Psychology, vol. 67, no 4, pp. 741-763. DOI: 10.1037//0022-3514.67.4.741

Shaffer B., Duckitt J. (2013) The Dimensional Structure of People's Fears, Threats, and Concerns and Their Relationship with Right-Wing Authoritarianism and Social Dominance Orientation. International Journal of Psychology, vol. 48, no 1, pp. 6-17. DOI: 10.1080/00207594.2012.696651

Smyth R. (2012) Political Preferences and Party Development in Post-Communist States. Demokratizatsiya, vol. 20, no 2, pp. 113-132.

Standing G. (2014) Precariat: The New Dangerous Class, Moscow: Ad Marginem (in Russian).

Stubager R. (2008) Education Effects on Authoritarian-Libertarian Values: A Question of Socialization. The British Journal of Sociology, vol. 59, no 2, pp. 327-350. DOI: $10.1111 /$ j.1468-4446.2008.00196.x

The Unemployment in Russia and Foreign Countries under the Conditions of Crisis (2015) The Analytical Centre under the Government of Russian Federation. Available at: https://ac.gov.ru/archive/files/publication/a/4987.pdf, accessed 31.08.2020 (in Russian).

Throsby D., Zednik A. (2011) Multiple Job-holding and Artistic Careers: Some Empirical Evidence. Cultural Trends, vol. 20, no 1, pp. 9-24. DOI: 10.1080/09548963.2011.540809 
Torche F., Lopez-Calva L.F. (2013) Stability and Vulnerability of the Latin American Middle Class. Oxford Development Studies, vol. 41, no 4, pp. 409-435. DOI: $10.1080 / 13600818.2013 .831060$

Toshchenko Z. (2017) From the Proletariat to the Precariat (about the Emergence of a New Class). Journal of the Belarusian State University. Sociology, no 3, pp. 95-101 (in Russian).

Vasilopoulos P., Lachat R. (2018) Authoritarianism and Political Choice in France. Acta Politica, vol. 53, no 4, pp. 612-634. DOI: 10.1057/s41269-017-0066-9

Visser M., Lubbers M., Kraaykamp G., Jaspers E. (2014) Support for Radical Left Ideologies in Europe. European Journal of Political Research, vol. 53, no 3, pp. 541-558. DOI: $10.1111 / 1475-6765.12048$

Vives A., Amable M., Ferrer M., Moncada S., Lloren C., Muntaner C., Benavides F., Benach J. (2013) Employment Precariousness and Poor Mental Health: Evidence from Spain on a New Social Determinant of Health. Journal of Environmental and Public Health, vol. 2013, pp. 1-10. DOI: 10.1155/2013/978656

Wheatley J. (2015) Identifying Latent Policy Dimensions from Public Opinion Data: An Inductive Approach. Journal of Elections, Public Opinion \& Parties, vol. 25, no 2, pp. 215-233. DOI: $10.1080 / 17457289.2014 .985222$

Wilson K. (2012) How Russians View Electoral Fairness: A Qualitative Analysis. Europe-Asia Studies, vol. 64, no 1, pp. 145-168. DOI: 10.1080/09668136.2012.635485

Zuckerman A.S., Kotler-Berkowitz L.A., Swaine L.A. (1998) Anchoring Political Preferences: The Structural Bases of Stable Electoral Decisions and Political Attitudes in Britain. European Journal of Political Research, vol. 33, no 3, pp. 285-321. DOI: 10.1111/1475-6765.00384 